\title{
Investigation of Thermochemical Reaction of Metallic Grooves Manufactured with Laser Micromachining in Liquid
}

\author{
Kwang H. Oh ${ }^{* 1}$, S. Z. Lee ${ }^{1}$ and S. H. Jeong ${ }^{2}$ \\ ${ }^{1}$ Laser Advanced System Industrialization Center, Jeonnam Technopark Stiftung \\ 329-3 Samtae-ri Nam-myeon Jangseong-gun Jeollanam-do, 515-893, Republic of Korea \\ *E-mail :sharkie@laser.re.kr \\ ${ }^{2}$ Department of Mechatronics, Gwangju Institute of Science and Technology \\ 1 Oryong-dong Buk-gu Gwangju Megalopolis, 500-712, Republic of Korea
}

\begin{abstract}
Chemical reaction governing the overall etching process is the most significant factor in the determination of etching characteristics in laser-induced etching. A method of the sample preparation for measuring chemistry of the etchant and etched metallic groove is demonstrated. Also, chemical analyses of the used etchant and etched groove and derivation of the possible reactions between the stainless steel 304 workpiece and phosphoric acid during laser irradiation and non-irradiation are carried out based on the measured data of XPS, UV-VIS absorption, and ICP-mass, respectively in this paper.
\end{abstract}

DOI: $10.2961 /$ jlmn.2016.01.0005

Keywords: laser material processing, laser-induced etching, thermochemical reaction, stainless steel 304, phosphoric acid

\section{Introduction}

Metallic microgroove is the key configuration of many micron feature sized structures such as micro heat pipe for microelectronics cooling [1], micro fuel cell [2], compact heat pump [3], microchemical reactor [4], etc. Due to their simple geometry, microgrooves are relatively easy to fabricate and thus widely adopted in the design of microdevices.

To fabricate microgrooves with size uniformity and shape clarity, microelectro-discharge-machining technique is mainly adopted. However, this method is not only slow but also suffers from tool wear. Even though silicon-based microgrooves of high precision can be readily fabricated using semiconductor manufacturing processing, they have disadvantages for application to an environment where high temperature and large thermal stresses are expected. With femtosecond pulsed laser with high peak intensity, ultra-fine micromachining with no thermal deformation is available. Nevertheless, femtosecond lasers are not widely utilized yet because of handling difficulty and high system price.

Alternatively, laser-induced thermochemical wet etching (denoted by 'laser-induced etching' in the following for simplicity) can be effectively utilized for the fabrication of metallic microgrooves. Laser-induced etching is a promising micromachining technique in which a focused laser beam irradiates a workpiece immersed in a liquid etchant to induce a thermochemical reaction between the etchant and the workpiece. Laser-induced etching is especially advantageous in the sense that it is a direct writing process requiring no mask, that is, the process is very simple. Also, comparing to the laser ablation micromachining, heat affected zone can be remarkably reduced, which allows not only the fabrication of small microgrooves but also in small pitches between grooves. In addition, using laserinduced etching, metallic microgrooves with high-aspect-ratio $(\geq 10)$ can be readily manufactured [5].

Meanwhile, stainless steel is one of the preferred metallic materials along with silver and copper for the fabrication of microdevices such as cooling elements of electronic modules due to its advantages of high strength, anti-corrosion, good thermal conductivity and plasticity. Hence, many previous researches verified that laser-induced etching is an effective micro machining technique for the fabrication of stainless steel microstructures to apply to microdevices $[6,7]$. In these earlier studies, phosphoric acid as an etchant has often been adopted to manufacture microstructures on stainless steel 304 workpiece because of low background etch rate.

For further qualitative approach, in laser-induced etching, investigation of the overall etching reaction or analysis of etching mechanism should be considered. However, since stainless steel is not a pure metal but an alloy material comprised the iron, chromium, nickel, and etc., the thermochemical reaction procedure between the stainless steel 304 and phosphoric acid cannot be easily understood. Even though some literatures introduced the reaction mechanism of stainless steel in a variety of acid solutions such as hydrochloric acid $(\mathrm{HCl})$, nitric acid $\left(\mathrm{HNO}_{3}\right)$, and phosphoric acid $\left(\mathrm{H}_{3} \mathrm{PO}_{4}\right)$, the majority swept the explanation of an exact reaction equation and depended upon the general neutralization principle.

In this study, the chemical reaction between the stainless steel 304 workpiece and phosphoric acid during the irradiation of laser beam is examined by utilizing the various chemical analysis equipment such as inductively coupled plasma-mass (ICP-mass) spectrometer, X-ray photoelectron spectrometer (XPS), and UV-VIS absorption spectrometer. Based on the measured data, the possible chemical reaction between the stainless steel 304 and phosphoric acid during the laser irradiation and non-irradiation period are derived systemically.

\section{Experiments}

\subsection{Microgrooves fabrication}

Figure 1 shows a schematic diagram of the experimental setup for laser-induced etching to fabricate metallic grooves. 


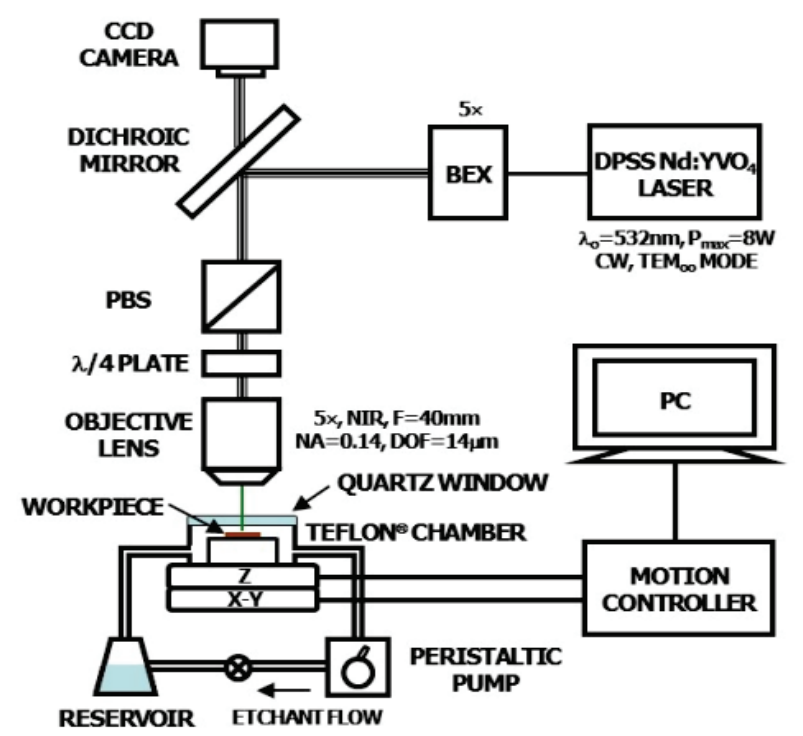

Fig. 1 Schematic diagram of the experimental setup.

A DPSS CW laser (Coherent Inc., VERDI-V8, $P_{\max }=8 \mathrm{~W}$ and $\lambda_{0}=532 \mathrm{~nm}$ ) was used as the heat source to locally induce thermochemical reaction between the etchant and the workpiece. The laser beam of $2.25 \mathrm{~mm}$ in diameter was expanded by five times using a beam expander and then tightly focused on the workpiece surface with an objective lens (Mitutoyo Corp., NIR $5 \times, f=40 \mathrm{~mm}, W D=37.5 \mathrm{~mm}, N A=0.14$ and $D O F=14 \mu \mathrm{m}$ ) after passing a linear polarizer, a $\lambda / 4$ plate and a quartz window for optical isolation and polarization control. For direct writing, a high resolution $(1 \mu \mathrm{m} / \mathrm{pulse})$ motorized X-Y-Z stage (Suruga Seiki Co. Ltd., KS701-20LMS) was used and a Teflon ${ }^{\circledR}$ chamber in which the workpiece was placed was installed on the X-Y-Z stage. A stainless steel foil (Goodfellow Corp., AISI $304, \mathrm{Fe} 72 / \mathrm{Cr} 18 / \mathrm{Ni10})$ of $500 \mu \mathrm{m}$ thickness and approximately $1 \times 1 \mathrm{~cm}^{2}$ size was used as the workpiece. Also, phosphoric acid $\left(\mathrm{H}_{3} \mathrm{PO}_{4}\right.$, Junsei Chemical Co. Ltd., $\left.85 \%\right)$ diluted with distilled water was used as the etchant. The etchant was circulated using a peristaltic pump in order to improve the etchant flow into the deep grooves and also to assist the removal of microbubbles from etching spot. All etching processes were monitored with a CCD camera. Etching results and chemical characteristics were analyzed using optical microscope (Olympus Corp., SZ11), ICP-mass spectrometer (Perkin Elmer Inc., ELAN 6100), XPS (Thermo Scientific, ESCALAB 250, Al Ka X-ray radiation $(h v=1486.6 \mathrm{eV})$, scan range of 0 to $1200 \mathrm{eV})$, and UV-VIS absorption spectrometer (JASCO Inc., V-660, scan range of 190 to $900 \mathrm{~nm}, \Delta \lambda=0.1 \mathrm{~nm}$ ) after an ultrasonic cleaning of the samples.

\subsection{Sample preparation}

In general, the surface chemistry and elemental composition of solid-state materials may be analyzed using the data of XPS or X-ray diffraction spectroscopy (XRD) whereas the spectra of IR and UV-VIS absorption are often employed to anticipate the chemical characteristics of liquid-state solution. Occasionally, chemical elements dissolved in an ionized state in the aqueous etchant can provide the critical information to enable the derivation of the ongoing chemical reactions. Therefore, to investigate the chemistry of the used $\mathrm{H}_{3} \mathrm{PO}_{4}$ using XPS, the etchant sample is prepared with the procedure represented in Fig. 2 and can be described as follows;

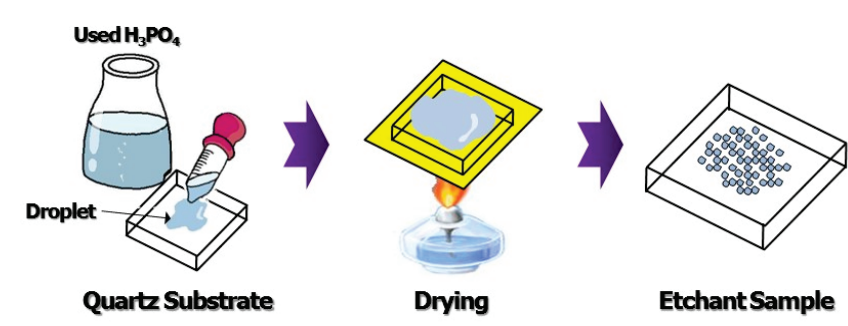

Fig. 2 Procedure of the etchant sample preparation for measurement of XPS.

i) $20 \sim 30 \mathrm{~mL}$ droplet of the used $10 \% \mathrm{H}_{3} \mathrm{PO}_{4}$ drops on the quartz substrate of $0.5 \times 0.5 \mathrm{~cm}^{2}$ in size.

ii) There is no certain chemical reaction occur between the used $10 \% \mathrm{H}_{3} \mathrm{PO}_{4}$ and the quartz substrate.

iii) Liquid etchant on the substrate is completely dried by using a dry oven or heater.

iv) Dried sample is used for the measurement of XPS with no evaporation under ultra-high vacuum condition.

Also, to measure the XPS spectra of the etched groove, the stainless steel 304 workpiece is polished by using a mechanical polisher along the groove length direction until the machined area of a groove is exposed. A polished workpiece is kept up a sealed state in the cleaned scale to protect from the possible contamination before measured.

\subsection{Chemical reaction analyses}

To investigate the accurate material removal mechanism during etching process, thermochemical reaction the workpiece and the etchant should be studied. Since the examination of chemical reaction cannot be carried out in real time, chemistry of the machined sample or used etchant measured by the various equipment for chemical analysis should be well considered to establish the process governing equation. In general, the chemical reaction between the stainless steel 304 and $\mathrm{H}_{3} \mathrm{PO}_{4}$ is very complex to analyze because the detailed reaction channels of iron, chromium, and nickel elements in stainless steel 304 are not clearly known. Therefore, few research literatures tried to find the chemical reaction mechanism or etching principle.

Nevertheless, Almeida et al. [8] studied the chemical reaction of stainless steels in phosphoric acid with various concentrations for a long exposure time of about two years. The authors demonstrated that iron chemically reacts with relatively low concentration of $\mathrm{H}_{3} \mathrm{PO}_{4}$ to produce soluble $\mathrm{Fe}_{3}\left(\mathrm{PO}_{4}\right)_{2}$ (ferrous phosphate or vivianite) as an etch by-product. Even though the authors carried out analysis of the chemical state conversion mechanism of iron with a variety of measurements such as Energy-dispersive X-ray spectroscopy (EDX), Fouriertransform infrared absorption spectroscopy (FT-IR), XRD, and Mössbauer spectroscopy, not only it took too much long time for experiments but also the process condition for inducing chemical reaction was room temperature which substantially different with locally high temperature circumstance like the laser irradiation.

As another approach, in an electrochemical test of corrosion behavior of stainless steel, Iken et al. [9] suggested the formation of iron, chromium, and nickel oxides through a reaction with water molecules dissolved inside $\mathrm{H}_{3} \mathrm{PO}_{4}$ at room temperature and also reported that the corrosion rate increased 
for increasing temperature due to higher corrosion current. However, no further information of chemical reaction between stainless steels and $\mathrm{H}_{3} \mathrm{PO}_{4}$ at high temperature except for surface oxidation mechanism and impedance variation of stainless steels were given in this literature.

Based these studies, the approach to analyze the thermochemical reaction occurring between the stainless steel 304 and $\mathrm{H}_{3} \mathrm{PO}_{4}$ during the laser irradiation and laser off period was tried the first time in this paper. The fabrication of stainless steel 304 microgrooves was accomplished at the conditions of $P$ (laser power $)=2 \mathrm{~W}, V($ scan speed of the laser beam $)=10 \mu \mathrm{m} / \mathrm{s}, C$ (etchant concentration) $=10 \%$ and $N$ (number of scans) $=5$. For chemical background the examinations of chemical binding and ionized state and of the groove and used etchant were achieved by XPS and UV-VIS absorption spectrometer, respectively. Also, to verify the non-selective etching of iron, chromium, and nickel in $\mathrm{H}_{3} \mathrm{PO}_{4}$, the stoichiometric analysis of the used etchant was carried out using ICP-mass spectrometer.

\section{Results and discussion}

\subsection{Surface temperature variations during the focused $\mathrm{CW}$ laser heating}

To investigate surface temperature variations of the workpiece during the focused $\mathrm{CW}$ laser irradiation, the workpiece temperature was calculated using the thermal model. The temperature rise induced by laser irradiation is a major concern in thermochemical reaction and the quality of the machined area depends significantly upon melting and solidification of the workpiece.

The maximum surface temperature variations as a function of irradiated laser power obtained by calculating a twodimensional heat conduction equation were represented in Fig 3. To calculate surface temperature of the workpiece during laser heating, laser spot diameter and dwelling time are necessarily demanded. Theoretically the laser spot diameter at the focus can be calculated using the Gaussian beam equation, $d=4 f \lambda_{d} / n \pi D$ where $f$ is focal length of the objective lens, $\lambda_{o}$ is the laser beam wavelength, $n$ is refractive index of the etchant and $D$ is the laser beam diameter entering the objective lens.

Using $n=1.343\left(10 \% \mathrm{H}_{3} \mathrm{PO}_{4}\right)$ [7] and $D=11.3 \mathrm{~mm}$, the laser spot diameter is estimated to be $1.8 \mu \mathrm{m}$. However, the measured beam spot diameter at the focus with a knife-edge method is around $14 \mu \mathrm{m}$ and this value is used as the representative spot diameter throughout the numerical calculation.

The dwelling time is the period during which a certain location on the workpiece surface is irradiated and can be expressed as follows [10];

$$
t_{D}=\frac{\pi D_{b}}{4 v}
$$

where, $D_{b}$ is beam diameter on the workpiece and $v$ is scan speed of the laser beam. For a $10 \mu \mathrm{m} / \mathrm{s}$ scan speed in the focused CW laser irradiation, the maximum dwelling time of the laser beam at a location was $1.1 \mathrm{~s}$.

In Fig. 3, the maximum surface temperature variations of the workpiece increases with the laser power, but the rate of increase gradually drops. Also, the maximum surface temperature during the focused $\mathrm{CW}$ laser heating can reach over $800 \mathrm{~K}$ at a relatively low laser power of $0.75 \mathrm{~W}$ and according to our previous research [11], these temperature values can induce chemical reaction between the stainless steel 304 and $\mathrm{H}_{3} \mathrm{PO}_{4}$.

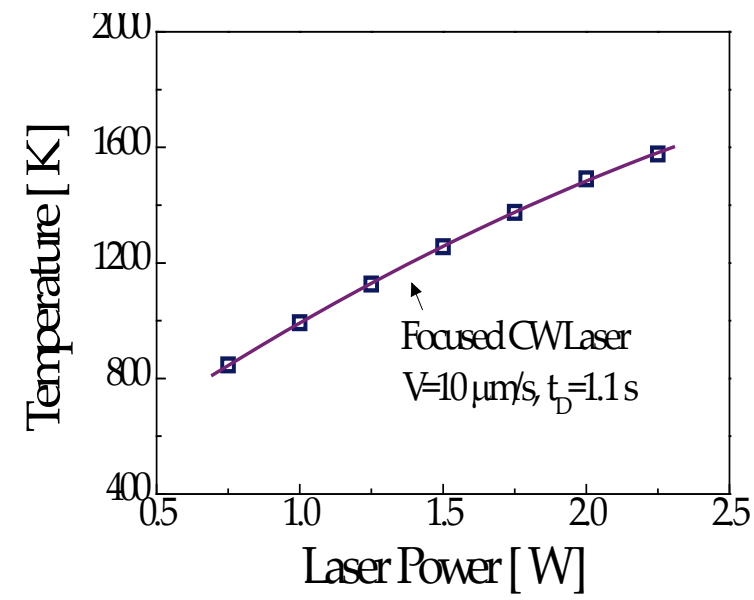

Fig. 3 Maximum surface temperature variations of the workpiece for varying laser powers. Scan speed is kept at the same value of $10 \mu \mathrm{m} / \mathrm{s}$.

3.2 Chemical reaction between the stainless steel 304 and phosphoric acid during the laser irradiation

The surface of austenitic stainless steel is protected by a native thin chromium oxide $\left(\mathrm{Cr}_{2} \mathrm{O}_{3}\right)$ layer (below several $\mathrm{nm}$ [12]) that nearly prohibits the progress of etching in $\mathrm{H}_{3} \mathrm{PO}_{4}$ under room temperature. However, when heat is supplied to the workpiece by laser irradiation raising the surface temperature above an etch threshold, thermally activated chemical reaction occurs and a local removal of the passivation layer is started [13].

Upon the laser irradiation, the chromium oxide passivation layer is being removed through thermochemical reaction, generating soluble chromium orthophosphate $\left(\mathrm{CrPO}_{4}\right)$ and $\mathrm{H}_{2} \mathrm{O}$ as by-products [14]. A possible reaction equation could be expressed as follows;

$$
\mathrm{Cr}_{2} \mathrm{O}_{3}+2 \mathrm{H}_{3} \mathrm{PO}_{4} \rightarrow 2 \mathrm{CrPO}_{4}+3 \mathrm{H}_{2} \mathrm{O}
$$

Under the region where the passivation layer is eliminated, the reactions of iron, chromium, and nickel with the etchant are expected to occur through several reaction channels.

To investigate possible chemical reactions, the chemistry of used etchant sampled after etching experiment was analyzed using XPS and UV-VIS absorption spectrometer. First, from the XPS data in Fig. 4, it is expected that ions that has the same binding energy as that of the O1s peak $(531.6 \mathrm{eV})$ in Fig. 4(b) are existent in the $\mathrm{H}_{3} \mathrm{PO}_{4}$ solution, which would be possibly $\mathrm{OH}^{-}$or $\mathrm{PO}_{4}^{3-}[15]$.

Figure 5 shows the UV-VIS absorption spectra of the used $\mathrm{H}_{3} \mathrm{PO}_{4}$ etchant comparison with that of the fresh etchant. The UV-VIS absorption spectra of the used etchant show two distinct peaks at the wavelengths of $625 \mathrm{~nm}$ and $410 \mathrm{~nm}$ those are not observed in the fresh etchant spectra and a sudden increase of absorption in the $300 \sim 350 \mathrm{~nm}$ regime. From an optical absorption measurement of $3 d$ transition elements in fused silica, Schultz [16] reported that Fe(III) had a strong absorption at the blue regime below $400 \mathrm{~nm}$ whereas $\mathrm{Cr}$ (III) and $\mathrm{Ni}(\mathrm{II})$ showed absorption at $625 \mathrm{~nm}$ and $410 \mathrm{~nm}$, respectively. Compared to these results, it is considered that the UV-VIS absorption data indicate the existence of ferric $\left(\mathrm{Fe}^{3+}\right)$, chromic $\left(\mathrm{Cr}^{3+}\right)$, and nickelous $\left(\mathrm{Ni}^{2+}\right)$ compounds as soluble by-products in the used etchant.

After the surface passivation layer is eliminated by incident laser light, the overall reaction between the stainless steel 304 


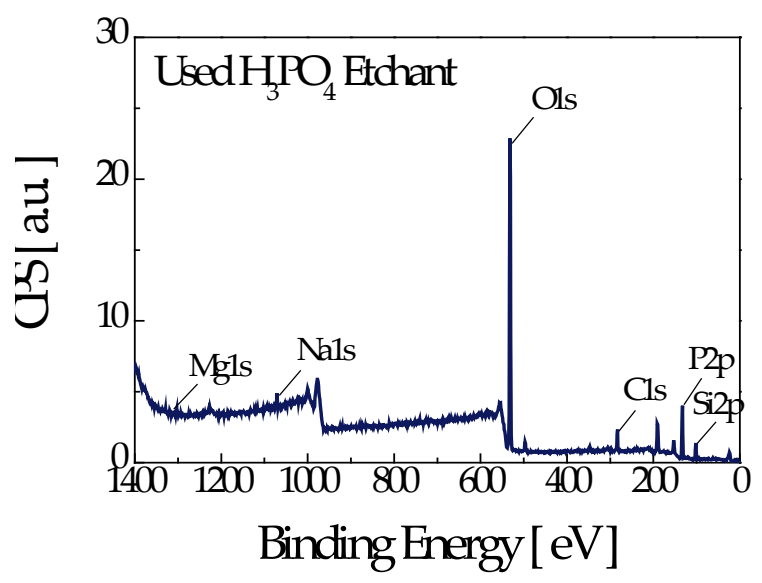

(a)

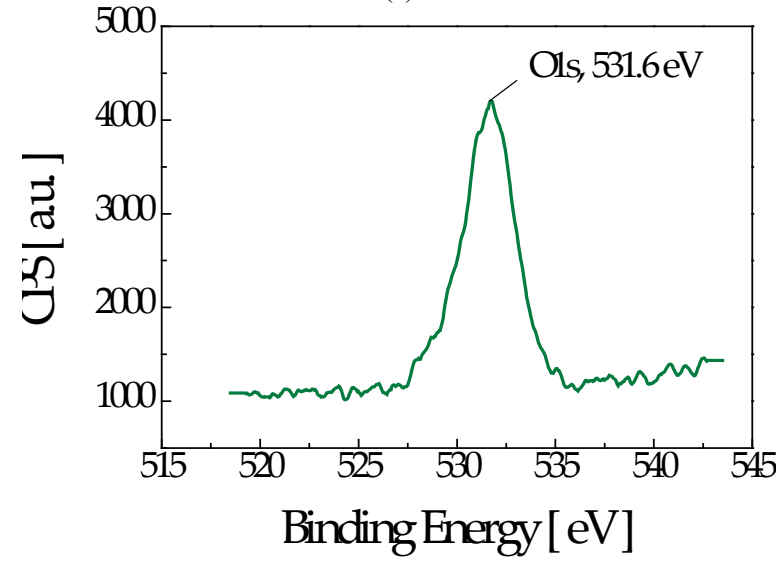

(b)

Fig. $4 \mathrm{X}$-ray photoelectron spectrographs for the (a) used $10 \% \mathrm{H}_{3} \mathrm{PO}_{4}$ solution and (b) rescaled $\mathrm{O} 1 \mathrm{~s}$ data.

and the etchant to form a groove by material removal is expected to occur as follows $[8,9]$;

$$
\begin{gathered}
3 \mathrm{Fe}+6 \mathrm{H}_{3} \mathrm{PO}_{4} \rightarrow 3 \mathrm{Fe}\left(\mathrm{H}_{2} \mathrm{PO}_{4}\right)_{2}+3 \mathrm{H}_{2}(\uparrow) \\
3 \mathrm{Fe}\left(\mathrm{H}_{2} \mathrm{PO}_{4}\right)_{2} \rightarrow \mathrm{Fe}_{3}\left(\mathrm{PO}_{4}\right)_{2}(\downarrow)+4 \mathrm{H}_{3} \mathrm{PO}_{4}
\end{gathered}
$$

Although Eqs. (2) and (3) only represent the reactions of iron, the reactions of chromium and nickel are anticipated to occur similarly. To verify the non-selective dissolution of iron,

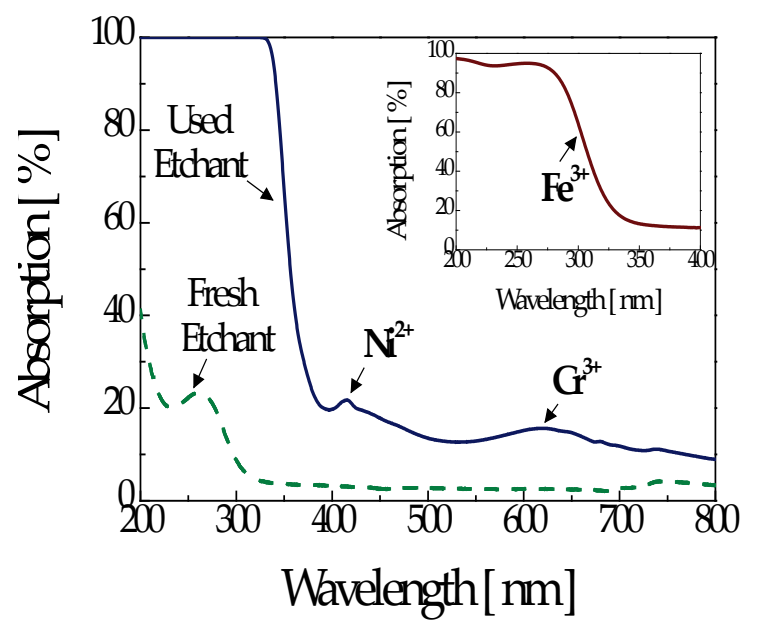

Fig. 5 UV-VIS absorption spectra of the used $\mathrm{H}_{3} \mathrm{PO}_{4}$ etchant (solid line) and fresh $\mathrm{H}_{3} \mathrm{PO}_{4}$ etchant (dash line).
Table 1 ICP-mass spectroscopy data of the used $\mathrm{H}_{3} \mathrm{PO}_{4}$ solution.

\begin{tabular}{c|c|c|c}
\hline Element & Mass & CPS & Concentration \\
\hline \hline $\mathrm{Cr}$ & 52 & $11,609.62 \mathrm{P}$ & $3.594 \mathrm{ppm}$ \\
\hline $\mathrm{Fe}$ & 57 & $898.950 \mathrm{P}$ & $14.73 \mathrm{ppm}$ \\
\hline $\mathrm{Ni}$ & 60 & $2,400.284 \mathrm{P}$ & $1.435 \mathrm{ppm}$ \\
\hline
\end{tabular}

chromium, and nickel in $\mathrm{H}_{3} \mathrm{PO}_{4}$ by the above equations, the composition of used etchant was analyzed using ICP-mass spectrometer and the results are shown in Table 1. The concentration values of each element in the Table 1 are almost equivalent to those in the bulk stainless steel 304, evidence that the dissolution of bulk material during laser-induced etching occurs non-selectively.

However, it should be noted that the $\mathrm{Fe}_{3}\left(\mathrm{PO}_{4}\right)_{2}$ (vivianite) [14] produced by the reaction represented by Eq. (3) is an insoluble compound. Similarly, the source of metallic elements identified from the ICP-mass measurements in Table 1 are expected from the insoluble precipitated by-products during the reactions between iron, chromium, nickel and the etchant. Therefore, these equations alone are insufficient to explain the formation of ions identified from the XPS and UV-VIS absorption measurements.

Accordingly, it is further expected that these exist several intermediate reaction channels to produce the ions identified from the XPS and UV-VIS absorption measurements, which possibly include soluble by-products $\mathrm{FePO}_{4}, \mathrm{CrPO}_{4}$, and $\mathrm{Ni}_{3}\left(\mathrm{PO}_{4}\right)_{2}[17,18]$.

\subsection{Chemical reaction between the stainless steel 304 and phosphoric acid under the laser off}

Not only the reactions during the etching while the laser is on but also the reactions after the laser is turned off can affect on the surface chemistry of the manufactured groove and also the composition of used etchant. After the laser is turned off, the etchant temperature will fall to about room temperature and at this condition, the iron, chromium, and nickel can be oxidized by reacting with $\mathrm{H}_{2} \mathrm{O}$ according to the following equations [9];

$$
\begin{aligned}
& \mathrm{Fe}+\mathrm{H}_{2} \mathrm{O} \rightarrow \mathrm{FeO}+2 \mathrm{H}^{+}+2 \mathrm{e}^{-} \\
& \mathrm{Cr}+\mathrm{H}_{2} \mathrm{O} \rightarrow \mathrm{CrO}+2 \mathrm{H}^{+}+2 \mathrm{e}^{-} \\
& \mathrm{Ni}+\mathrm{H}_{2} \mathrm{O} \rightarrow \mathrm{NiO}+2 \mathrm{H}^{+}+2 \mathrm{e}^{-}
\end{aligned}
$$

The $\mathrm{FeO}$ and $\mathrm{CrO}$ are subsequently further oxidized by a dissolution-precipitation mechanism as follows, whereas for the $\mathrm{NiO}$ only certain degree of thickening is expected.

$$
\begin{gathered}
2 \mathrm{FeO}+\mathrm{H}_{2} \mathrm{O} \rightarrow \mathrm{Fe}_{2} \mathrm{O}_{3}+2 \mathrm{H}^{+}+2 \mathrm{e}^{-} \\
2 \mathrm{Cr}+\mathrm{H}_{2} \mathrm{O} \rightarrow \mathrm{Cr}_{2} \mathrm{O}_{3}+2 \mathrm{H}^{+}+2 \mathrm{e}^{-}
\end{gathered}
$$

It is further expected that the $\mathrm{Fe}_{2} \mathrm{O}_{3}$ produced by the reaction described by Eq. (7) reacts with the etchant, generating soluble $\mathrm{FePO}_{4}$ and $\mathrm{H}_{2} \mathrm{O}$ as by-products, by following reaction equation [19];

$$
\mathrm{Fe}_{2} \mathrm{O}_{3}+2 \mathrm{H}_{3} \mathrm{PO}_{4} \rightarrow 2 \mathrm{FePO}_{4}+3 \mathrm{H}_{2} \mathrm{O}
$$




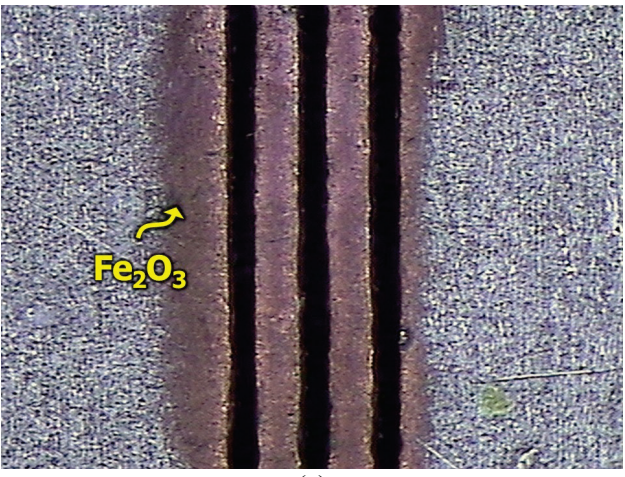

(a)

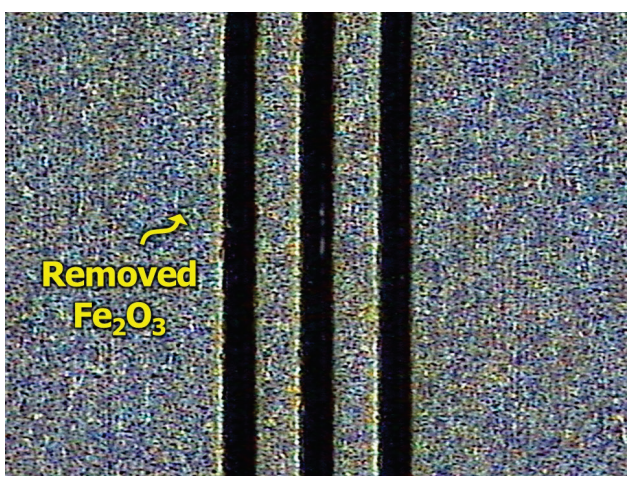

(b)

Fig. 6 Top views of the microgroove with (a) reddish $\mathrm{Fe}_{2} \mathrm{O}_{3}$ compound and (b) clean surface removed $\mathrm{Fe}_{2} \mathrm{O}_{3}$ compound. Process conditions is $P=2 \mathrm{~W}, V=10 \mu \mathrm{m} / \mathrm{s}, C=10 \%\left(\mathrm{H}_{3} \mathrm{PO}_{4}\right)$ and $N=5$.

From the XPS spectra of etched sidewall of the microgrooves, it was observed that the binding energy of $\mathrm{Fe} 2 \mathrm{p} 3$ peak about $711.8 \mathrm{eV}$ agrees closely to that of $\mathrm{FePO}_{4}\left(\mathrm{E}_{\mathrm{b}}=711.0 \mathrm{eV}\right)$ [14]. This result supports that the reaction between $\mathrm{Fe}_{2} \mathrm{O}_{3}$ and the etchant in Eq. (9) actually occurs after the laser in turned off.

For further verification of Eq. (7), the chemistry over the microgrooves right after the fabrication and after left in the etchant for about 4 hours are examined. When the workpiece was taken out of the etchant immediately after etching, the reddish stain of $\mathrm{Fe}_{2} \mathrm{O}_{3}$ remained around the microgroove as shown in Fig 6(a).

However, when the workpiece was left in the etchant for 4 hours, the stain observed in Fig 6(a) completely disappeared (see Fig. 6(b)), implying that the $\mathrm{Fe}_{2} \mathrm{O}_{3}$ layer underwent through the reaction represented by Eq. (9) to produce $\mathrm{FePO}_{4}$. Since $\mathrm{FePO}_{4}$ plays the role of a passivation layer just as the natively formed $\mathrm{Cr}_{2} \mathrm{O}_{3}$ layer on bulk stainless steel 304, the processed microgrooves can be protected from the contamination and corrosion.

\section{Conclusion}

The objectives of this study were to investigate the chemical reaction between the stainless steel 304 and phosphoric acid during the laser irradiation and non-irradiation conditions. To verify possible chemical reaction, the various analytical equipment such as XPS, UV-VIS absorption spectrometer and ICP-mass spectrometer were employed.

During the laser beam is locally irradiated on the stainless steel 304 workpiece surface, the reactions of iron, chromium, and nickel with $\mathrm{H}_{3} \mathrm{PO}_{4}$ etchant are expected to occur through several reaction channels direct after $\mathrm{Cr}_{2} \mathrm{O}_{3}$ passivation layer is eliminated by incident laser beam. Consequently, XPS and ICPmass spectroscopy data implied that the dissolution of bulk stainless steel 304 material during laser-induced etching occurs non-selectively. From these analyses, it was identified that $\mathrm{FePO}_{4}, \mathrm{CrPO}_{4}$, and $\mathrm{Ni}_{3}\left(\mathrm{PO}_{4}\right)_{2}$ possibly existed as soluble byproducts in the used $\mathrm{H}_{3} \mathrm{PO}_{4}$ etchant.

On the other hand, under the laser off, which the etchant temperature falls to room temperature condition, the iron, chromium, and nickel are probably oxidized by reacting with $\mathrm{H}_{2} \mathrm{O}$. Especially, the iron is further oxidized by a dissolutionprecipitation mechanism, leading to the reddish stain of $\mathrm{Fe}_{2} \mathrm{O}_{3}$.

However, it is verified that $\mathrm{Fe}_{2} \mathrm{O}_{3}$ reacts sequentially with $\mathrm{H}_{3} \mathrm{PO}_{4}$, resulting in $\mathrm{FePO}_{4}$ as a by-product and eventually, the fabrication of metallic microgrooves with good surface quality can be achieved by produced $\mathrm{FePO}_{4}$ passivation layer.

It is expected that the chemical reaction results between stainless steel 304 and phosphoric acid and multi-directionally analyzed data can be effectively utilized the further corrosion research and analysis of other physicochemical characteristics between the related metallic material and etchant solution.

\section{Acknowledgments}

This work was supported by the Industrial Technology Research Infrastructure Program (N0000012, Infrastructure establishment on the laser processing system for the next generation micro applications) funded by the Ministry of Trade, Industry and Energy (MOTIE, Republic of Korea).

\section{References}

[1] M. Le. Berre, S. Launay, V. Sartre and M. Lallemand: J. Micromech. Microeng., 13, (2003), 436.

[2] S. J. Lee, A. Chang-Chien, S. W. Cha, R. O’Hayre, Y. I. Park, Y. Saito and F. B. Prinz: J. Power Sources, 112, (2002), 410.

[3] Y. Yokoyama, M. Takeda, T. Umemoto and T. Ogushi: Sensors Actuators A, A111, (2004), 123.

[4] D. Erickson and D. Li: Int. J. Heat Mass Transfer, 45, (2002), 3759.

[5] S. W. Son, M. K. Lee, Kwang H. Oh and S. H. Jeong: J. Laser Appl., 18, (2006), 131.

[6] R. Nowak and S. Metev: Appl. Phys. A, 63, (1996), 133.

[7] Kwang H. Oh. M. L. Lee and S. H. Jeong: J. Micromech. Microeng., 16, (2006), 1958.

[8] E. Almeida, D. Pereira, M. O. Figueiredo, V. M. M. Lobo and M. Morcillo: Corros. Sci., 39, (1997), 1561.

[9] H. Iken, R. Basseguy, A. Guenbour and A. Ben Bachir: Electrochim. Acta, 52, (2007), 2580.

[10] T. A. Mai and G. C. Lim: J. Laser Appl., 16, (2004), 221.

[11] Kwang H. Oh, J. B. Park, S. I. Cho, H. D. Im and S. H. Jeong: Appl. Surf. Sci., 255, (2009), 9835.

[12] M. Abdallah: Mater. Chem. Phys., 82, (2003), 786.

[13] A. Mora, M. Haase, T. Rabbow and P. J. Plath: Phys. Rev. E, 72, (2005), 061604-1.

[14] A. R. Pratt: Phys. Chem. Miner., 25, (1997), 24.

[15] R. Nowak, S. Metev and G. Sepold: Proc. of SPIE, 2207, (1994), 633

[16] Peter C. Schultz: J. Am. Ceram. Soc., 57, (1974), 309.

[17] R. R. Viana and R. Prado: Proc. Int. Symp. Granitic Pegmatites : The State of the Art, Porto, (2007).

[18] F. Petit, H. Debontride, M. Lenglet, G. Juhel and D. Verchere: Appl. Spectroscopy, 49, (1995), 207.

[19] Website: http://www.team.net/sol/tech/deruster.html. 